\title{
Mengembangkan Kecakapan Abad 21 Mahasiswa Melalui Model Pembelajaran Inkuiri
}

\author{
Muhammad Qudrat Wisnu Aji13 \\ wisnu.aji@kemdikbud.go.id
}

Abstract: According to the World Economic Forum report, the gap between the skills learned and the skills needed is widening. This has happened since the traditional learning styles have proven to fail to equip graduates with the skills they need to succeed in the world of work. Workers in the latest era need to have the skills to collaborate, communicate and solve problems (21st century skills). To meet the demands of 21st century skills there must be an important step of change, namely changing traditional teacher-centered learning patterns into student-centered learning patterns. One innovation learning model that is considered to be in line with the shift in learning paradigm is inquiry based learning. Inquiry-based learning is the one involving students in finding important and meaningful solution through investigation and collaboration with others. Inquiry learning follows the following steps: (1)planning, (2) retrieving, (3) processing, (4) creating, (5) sharing, and (6) evaluating. With these general principles, Inquiry-Based Learning guides the actions of 21 st Century learners. Furthermore, through the inquiry process, students develop the Skill Set of 21st Century Learners skills, namely: 1) Learning and innovation consisting of critical thinking and problem solving, communication and collaboration of creativity and innovation; 2) Digital Literacy Skill consisting of information literacy, media literacy and ICT literacy; 3) Career and life skills consisting of flexibility and adaptability, self-initiative and direction, social and crosscultural interaction, productivity and accountability, leadership and accountability

Keywords: Inquiry-Based Learning, 21st Century Skills, Model

\footnotetext{
${ }^{13}$ Sekretariat Direktorat Jenderal Guru dan Tenaga Kependidikan, Kemendikbud
} 


\section{PENDAHULUAN}

$\mathrm{P}$ ekembangan teknologi informasi dan komunikasi demikian pesat dan telah mengubah tatanan kehidupan manusia saat ini. Dunia pendidikan dikritik lambat merespon perubahan ini dibandingkan dengan kalangan industri. Perubahaan dunia industri menciptakan produk dan jasa spesifik yang sesuai konsumen dari segmentasi generasi tersebut. Dunia pendidikan belum banyak meengembangkan karakterisik anak muda dari setiap generasi tersebut dalam perancangan kurikulum maupun proses pembelajaran. Padahal Generasi $Y$ yang lahir pada awal era digital sangat berbeda dibandingkan dengan Generasi Z yang lahir pada era digital (Sukmana, 2018).

Pada saat ini, dunia pendidikan tinggi merasakan kesenjangan (gap) generasi ini. Dosen lahir sebagai Generasi X (atau sebelumnya), menempuh pendidikan pada era generasi $Y$, mendidik mahasiswa dari Generasi Z agar mereka dapat berkarya pada periode generasi Alfa. Tidak ada jalan lain selain pendidik dan instusi pendidikan harus mau berubah untuk merespon perubahan zaman tersebut.

Saat ini, pendidikan berada di masa pengetahuan (knowledge age) dengan percepatan peningkatan pengetahuan yang luar biasa. Percepatan peningkatan pengetahuan ini didukung oleh penerapan media dan teknologi digital yang disebut dengan information super highway. Gaya kegiatan pembelajaran pada masa pengetahuan (knowledge age) harus disesuaikan dengan kebutuhan pada masa pengetahuan (knowledge age). Bahan pembelajaran harus memberikan desain yang lebih otentik untuk melalui tantangan di mana peserta didik dapat berkolaborasi menciptakan solusi memecahkan masalah pelajaran. Pemecahan masalah mengarah ke pertanyaan dan mencari jawaban oleh peserta didik yang kemudian dapat dicari pemecahan permasalahan dalam konteks pembelajaran menggunakan sumber daya informasi yang tersedia (Trilling \& Hood 1999).

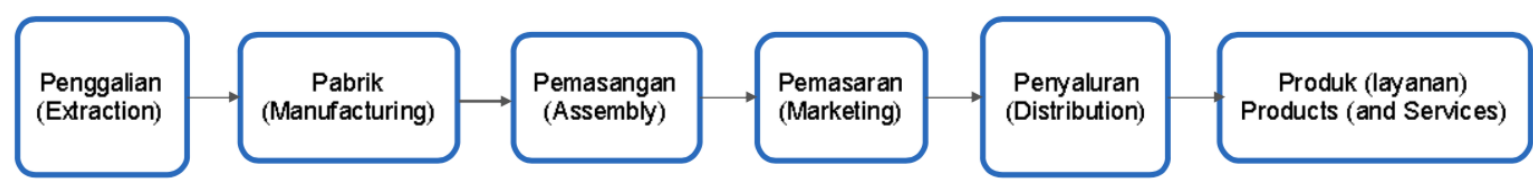

Gambar 1. Alur Perubahan Masa Industri (Industrial Age)

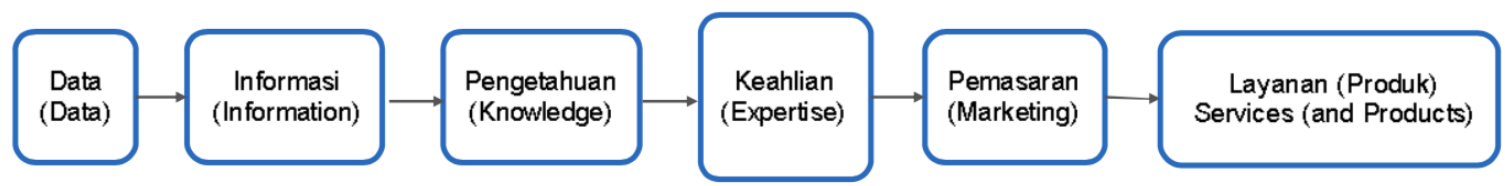

Gambar 2. Alur Perubahan Masa Pengetahuan (Knowledge Age)

Kecanggihan teknologi informasi telah memungkinkan terjadinya pertukaran informasi yang cepat tanpa terhambat oleh batas ruang dan waktu. Kemajuan suatu bangsa dalam era informasi sangat tergantung pada kemampuan masyarakatnya dalam memanfaatkan pengetahuan untuk meningkatkan produktifitas. Karakteristik masyarakat seperti ini dikenal dengan istilah masyarakat berbasis pengetahuan (knowledge-based society). Siapa yang menguasai pengetahuan maka ia akan mampu bersaing dalam era global. Oleh karena itu, setiap perguruan tinggi berlomba untuk mengintegrasikan media seperti teknologi informasi dengan tujuan dapat bersaing dalam era global. 
Tucker (2001) mengidentifikasi adanya sepuluh tantangan di abad 21 yaitu: (1) kecepatan (speed), (2) kenyamanan (convinience), (3) gelombang generasi (age wave), (4) pilihan (choice), (5) ragam gaya hidup (life style), (6) kompetisi harga (discounting), (7) pertambahan nilai (value added), (8) pelayananan pelanggan (costumer service), (9) teknologi sebagai andalan (techno age), (10) jaminan mutu (quality control). Ciri abad ke-21 adalah meningkatnya interaksi warga dunia secara langsung maupun tidak langsung yang ditopang oleh kemajuan Teknologi Informasi dan Komunikasi. Melihat kenyataan tersebut, Perguruan Tinggi harus mempersiapkan mahasiswa untuk mengambil peran dalam hal tersebut. Dunia pendidikan hendaknya sudah melatih mahasiswa untuk berpikir kritis dalam merespon berbagai informasi. Agar dapat menang dalam persaingan, tiga keterampilan yang harus dimiliki di abad ke-21 yaitu: (1) life and career skills, (2) learning and innovation skills, dan (3) Information media and technology skills. Lebih khusus untuk learning and innovation skills ada 4 kompetensi yang harus dimiliki (dikenal dengan sebutan 4C), yaitu: Communicaon, Collaboraon, Critical Thinking, dan Creavity. British Council memperkenalkan istilah Core Skills (keterampilan inti), yaitu keterampilan yang harus dimiliki di abad ke-21, meliputi keterampilan: critical thinking and problem solving, creativity and imagination, leadership, digital literacy, collaboration and communication, dan ciztienship (Ball, Joyce, \& Butcher, 2016).

Hasil penelitian menunjukkan bahwa Pada saat yang sama, ada desakan untuk memastikan kaum muda memiliki keterampilan yang dibutuhkan untuk bersaing dan berhasil dalam angkatan kerja. Hasil penelitian menunjukkan bahwa ada kesenjangan antara persiapan akademik dan keterampilan tenaga kerja (Cassel, 2018; Sparks \& Waits, 2011). Secara khusus, permintaan dari dunia usaha adalah tenaga kerja yang memiliki keterampilan seperti kerja tim, kreativitas, kebiasaan kerja yang kuat, dan keterampilan sosial (Olson, 2016). Dengan demikian, di samping kekuatan karakter perusahaan membutuhkan keterampilan abad ke-21 untuk memastikan kaum muda siap bersaing dalam angkatan kerja yang terus berubah. Untuk mengatasi masalah ini, harus diimplementasikan pembelajaran abad 21.

Pembelajaran abad 21 secara sederhana diartikan sebagai pembelajaran yang memberikan kecakapan abad 21 kepada peserta didik, yaitu 4C yang meliputi: (1) Communication (2) Collaboration, (3) Critical Thinking and Problem Solving, dan (4) Creative and Innovative. Berdasarkan Taksonomi Bloom yang telah direvisi oleh Krathwoll dan Anderson, kemampuan yang perlu dicapai siswa bukan hanya LOTS (Lower Order Thinking Skills) yaitu C1 (mengetahui) dan C-2 (memahami), MOTS (Middle Order Thinking Skills) yaitu C3 (mengaplikasikan) dan C-4 (mengalisis), tetapi juga harus ada peningkatan sampai HOTS (Higher Order Thinking Skills), yaitu C-5 (mengevaluasi), dan C-6 (mengkreasi), untuk dapat meningkatkan kecakapan abad 21 mahasiswa, diperlukan suatu upaya yang dapat diterapkan pada kegiatan pembelajaran. Upaya tersebut dapat dilakukan dengan berbagai cara, salah satunya dengan menerapkan suatu model pembelajaran yang dapat mendukung peningkatan kecakapan abad 21 mahasiswa. Ada beberapa model pembelajaran yang dapat diterapkan dalam mata kuliah ini, misalnya (1) Problem Based Learning, (2) Model Pembelajaran Discovery, (3) Model Pembelajaran Inkuiri, dan (4) Project Based Learning. Salah satu model pembelajaran berorientasi konstruktivistik yang berkembang saat ini adalah Model Pembelajaran Inkuiri (Eick \& Reed, 2002). Pembelajaran berbasis inkuiri adalah pembelajaran yang melibatkan siswa dalam menemukan solusi yang penting dan bermakna melalui penyelidikan dan kolaborasi dengan orang lain (Blumenfeld, et al., 1991 dalam Al-Musawi et.al, 2012). Lingkungan belajar inkuiri yang dirancang dengan baik dapat meningkatkan pengalaman belajar (Dede, 1998; Halpern., 2014). Blumberg (2000) berpendapat bahwa penyelidikan dapat menumbuhkan kemampuan berpikir kritis dan keterampilan pengolahan informasi. Penyelidikan cenderung untuk meningkatkan kemampuan belajar mandiri pada siswa. (Kühne, 1995) 
Melalui pendekatan tersebut, siswa memperoleh pemahaman tentang prinsip kunci dan konsep kunci, mengembangkan kebiasaan berpikir, dan belajar untuk mengokunikasikan pengetahuan mereka kepada orang lain (Brown \& Champione, 1995 dalam Al-Musawi et.al, 2012). Forum diskusi dapat digunakan untutk meningkatkan hasil belajar siswa (Montero, et al., 2007.)

Pembelajan berbasis inkuiri terbukti mampu menumbuhkan kecakapan abad 21 (4C) (Holaday \& Buckley, 2008; Soltis, et.al, 2015). Chen \& Chen (2012) dalam penelitiannya menemukan bahwa pembelajaran berbasis inkuiri juga mampu meningkatkan hasil belajar. Dalam berbagai pengalaman, pembelajaran berbasis penyelidikan, terutama penyelidikan terbuka, membuktikan bahwa siswa lebih mudah memahami topik baru. Berdasarkan uraian tersebut, tulisan ini ingin menjawab permasalahan tentang bagaimana mengimplementasikan model pembelajaran "Inkuiri" dalam mengembangkan kecakapan abad 21 mahasiswa.

\section{TINJAUAN LITERATUR}

\section{Konsep Model pembelajaran inkuiri}

Pengertian pembelajaran berbasis inkuiri dalam makalah ini merujuk pada pendapat Levy et.al. (2009) yang mendefinisikan pembelajaran berbasis inkuiri sebagai suatu pendekatan pedagogik dimana kegiatan eksplorasi, investigasi atau penelitian dilakukan untuk mendorong pengalaman belajar. Semua kegiatan belajar mengajar dan sumber daya yang dirancang untuk mendukung proses penyelidikan. Titik tolak pembelajaran berbasis inkuiri adalah pertanyaan dari siswa, guru atau dengan negosiasi di antara mereka (Ekdahl, 2010). Dengan akar teoritis dalam karya John Dewey dan Jerome Bruner, pembelajaran berbasis inkuiri adalah pendekatan yang melibatkan siswa secara eksplisit dengan proses penciptaan pengetahuan, dan yang mengembangkan disposisi dan kemampuan relevansi khusus untuk hidup dan bekerja di dunia yang sangat kompleks dan menantang (Brew, 2006 dalam Levy et.al., 2009). Miranda \& Hermann (2012) dalam eksperimennya menemukan tahapan dalam pembelajaran berbais inkuiri dengan sebutan 7E (Engage, Elicit, Explore, Explain, Elaborate, Evaluate, Extend). Bishop et al., (2004) memberikan tahapan yang berbeda dalam pembelajaran berbasis inkuiri. Pembelajaran berbasis inkuiri digambarkan sebagai siklus atau spiral, sebagai berikut :

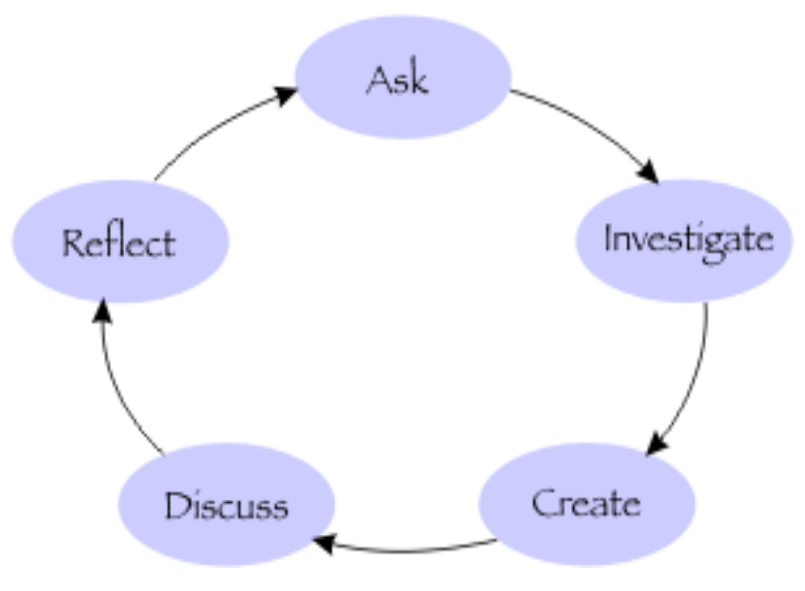

Gambar 3: Siklus Pembelajaran berbasis inkuiri (Bishop, et.al. 2004; Villavicencio, 2000) 
Gambar diatas menyatakan bahwa tahapan inkuiri terdiri dari 5 tahap yaitu fase bertanya (ask), fase penyelidikan (investigate), menghasilkan (create), diskusi (discuss), dan refleksi (reflect). Setiap langkah dalam proses ini secara alami mendorong munculnya pertanyaan baru, investigasi, dan peluang untuk "teachable moments" (Villavicencio, 2000). Siklus Pembelajaran berbasis inkuiri menginformasikan bahwa perumusan pertanyaan, investigasi, penciptaan solusi atau respon yang tepat, diskusi dan refleksi berhubungan dengan hasil belajar (Bishop, et.al. 2004).

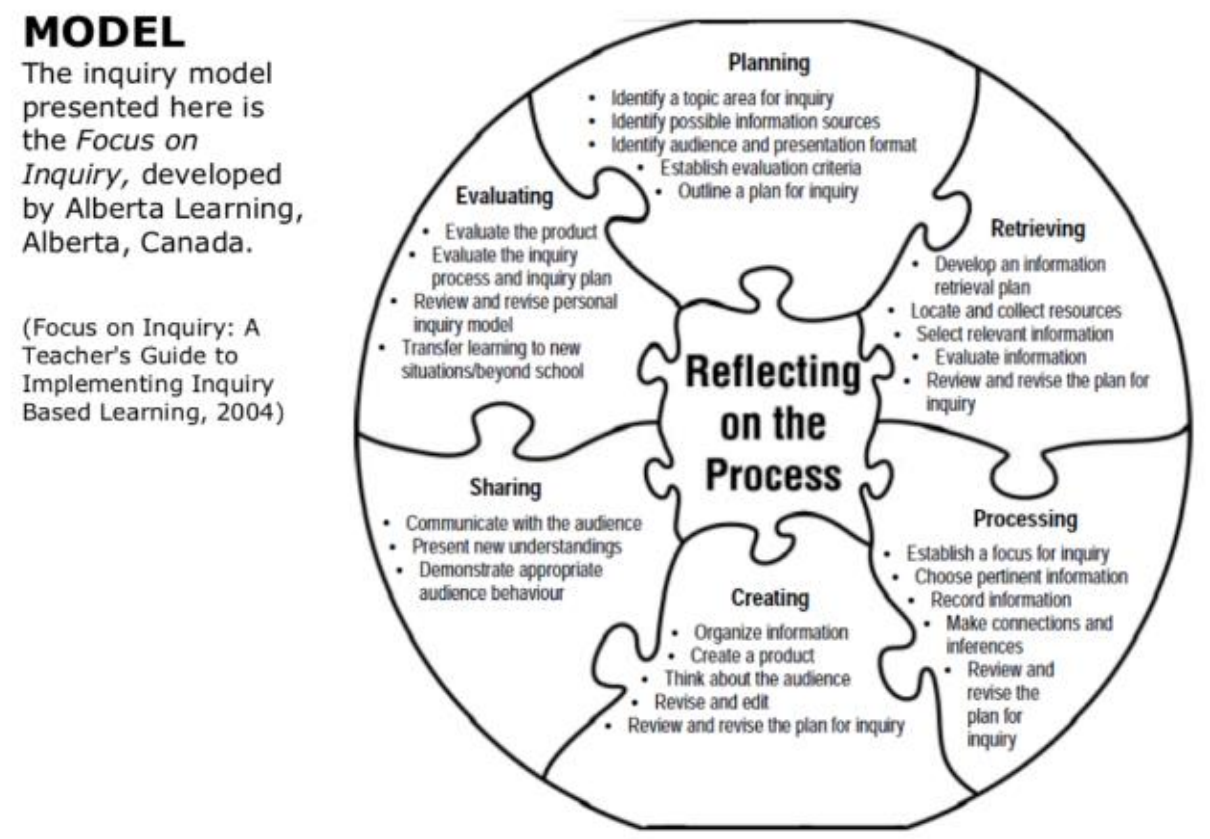

Gambar 4 Siklus Model Inkuiri (Alberta Learning 2004)

Sintak model inkuri yang lain dikemukakan oleh Alberta Learning yang disebut dengan The Focus on Inquiry. Sintak dimulai dari 1) Planning, 2) Retrieving; 3) Processing; 4) Creating; 5) Sharing dan 6) Evaluating. Sanjaya (2008) menyatakan bahwa pembelajaran inkuiri mengikuti langkah-langkah (1) orientasi, (2) merumuskan masalah, (3) merumuskan hipotesis, (4) pengumpulan data, (5) menguji hipotesis dan (6) merumuskan kesimpulan. Pada tahap Orientasi dosen melakukan langkah untuk membina suasana atau iklim pembelajaran yang kondusif. Merumuskan masalah merupakan langkah membawa siswa pada suatu persoalan yang mengandung teka-teki. Siswa didorong untuk mencari jawaban yang tepat. Proses mencari jawaban itulah yang sangat penting dalam pembelajaran inkuiri. Melalui proses tersebut siswa akan memperoleh pengalaman berharga sebagai upaya mengembangkan mental melalui proses berpikir. Hipotesis adalah jawaban sementara dari suatu permasalahan yang dikaji. Dan perlu diuji kebenarannya. Salah satu cara yang dapat dilakukan guru adalah dengan mengajukan berbagai pertanyaan yang dapat mendorong siswa untuk dapat merumuskan jawaban sementara. Mengumpulkan data adalah aktifitas menjaring informasi yang dibutuhkan untuk menguji hipotesis yang diajukan. Menguji hipotesis adalah menentukan jawaban yang dianggap diterima sesuai dengan data atau informasi yang diperoleh berdasarkan pengumpulan data. Merumuskan kesimpulan adalah proses mendeskripsikan temuan yang diperoleh berdasarkan hasil pengujian hipotesis. Untuk mencapai kesimpulan yang akurat sebaiknya guru mampu menunjukkan 
pada siswa data mana yang relevan (Sanjaya, 2008). Pembelajan berbasis inkuiri terbukti mampu menumbuhkan kemampuan berpikir kritis (Holaday \& Buckley, 2008; Soltis et.al, 2015). Chen \& Chen (2012) dalam penelitiannya menemukan bahwa pembelajaran berbasis inkuiri juga mampu meningkatkan hasil belajar. Dalam berbagai pengalaman, pembelajaran berbasis penyelidikan, terutama penyelidikan terbuka, membuktikan bahwa siswa lebih mudah memahami topik baru.

\section{Kecakapan Abad 21}

Beberapa organisasi telah berupaya mengumpulkan daftar keterampilan abad ke-21, melalui tinjauan literatur, pertimbangan hasil survei seperti yang baru saja ditinjau, panel ahli, dan sejenisnya. Kemitraan untuk Keterampilan Abad 21 (Partnership for 21st Century Skills, 2002), didirikan pada tahun 2002 oleh Ken Kay dan Diny Golder-Dardi dengan dukungan dari AOL, Cisco, Microsoft, dan Departemen Pendidikan A.S., antara lain adalah salah satu yang pertama dari kelompok-kelompok ini. la memiliki misinya "untuk memposisikan kesiapan abad ke-21 di pusat pendidikan K12 AS dengan membangun kemitraan kolaboratif di antara para pemimpin pendidikan, bisnis, masyarakat, dan pemerintah" P21, demikian sebutannya, mengusulkan serangkaian hasil peserta didik abad ke-21, termasuk kedua subjek inti (3R); dan yang baru, termasuk keterampilan belajar dan inovasi (4 C: critical thinking, communication, collaboration, creativity); information, media, and technology skills; and life and career skills. P21 juga mengusulkan bahwa hasil siswa abad ke-21 ini dapat mempengaruhi standar dan penilaian, kurikulum dan pengajaran, pengembangan profesional, dan lingkungan belajar.

Kelompok dan organisasi lain telah mengusulkan taksonomi serupa. The Assessing and Teaching of 21st Century Skills (ATC21S), disponsori oleh Cisco, Intel, dan Microsoft, mendefinisikan keterampilan abad ke-21 (Binkley, et al, 2010), sebagai berikut:

1. Ways of Thinking (creativity and innovation; critical thinking, problem solving, and decision making; learning to learn and metacognition)

2. Ways of Working (communication; collaboration and teamwork)

3. Tools for Working (information literacy; information technology and communication literacy)

4. Living in the World (life and career; personal and social responsibility)

National Research Council (NRC) dan National Academy of Sciences (NAS) telah melakukan beberapa studi keterampilan abad ke-21 selama beberapa tahun terakhir, dimulai pada tahun 2005 dengan lokakarya yang diadakan untuk membahas peran pendidikan K-12 dalam mengembangkan keterampilan abad ke-21 (National Research Council, 2008), menindaklanjuti dengan lokakarya tentang peran keterampilan abad ke-21 dalam pendidikan sains (NRC, 2010), yang berfokus secara khusus pada masalah penilaian (NRC, 2011), dan kemudian upaya terbaru tentang pembelajaran yang lebih dalam dan keterampilan abad ke-21 (NRC, 2012). Selama lokakarya, sebuah organisasi tripartit keterampilan abad ke-21 telah terbukti berfungsi sebagai kerangka kerja organisasi yang berguna. Mengadopsi organisasi itu dan memasukkannya ke dalam komponen yang diidentifikasi di sini, kami mendapatkan sesuatu seperti berikut:

1. Keterampilan kognitif-pemikiran kritis, pemecahan masalah, kreativitas

2. Keterampilan interpersonal—keterampilan komunikasi, keterampilan sosial, kerja tim, kepekaan budaya, berurusan dengan kesulitan

3. Keterampilan intrapersonal—manajemen diri, pengaturan diri, manajemen waktu, pembelajaran seumur hidup, kemampuan beradaptasi, fungsi eksekutif 
Tentu saja, ada tumpang tindih di antara kategori-kategori ini. Sebagai contoh, keterampilan komunikasi memiliki komponen kognitif dan interpersonal, dan keterampilan lain yang serupa dapat diklasifikasikan secara silang. Tapi ini adalah kerangka kerja yang berguna untuk membantu berpikir tentang penilaian dan masalah lainnya.

Keterampilan abad ke-21 yang sangat diperlukan oleh lulusan untuk berprestasi dan berkompetisi di abad ke-21 telah diidentifikasi oleh The Partnership for 21st Century Skills (2008). Keterampilan ini dapat meningkatkan kemampuan daya jual (marketability), kemampuan bekerja (employability), dan kesiapan menjadi warga negara (readiness for citizenship) yang baik.

The Partnership for 21st Century Learning (2015) telah mengembangkan visi belajar yang dikenal dengan nama The Framework for 21st Century Learning. Kerangka ini menjelaskan keterampilan, pengetahuan, dan keahlian yang harus dikuasai oleh peserta didik agar berhasil dalam kerja dan kehidupan. Kerangka ini meliputi mata pelajaran utama dan tema abad ke-21, hasil belajar peserta didik abad ke-21, dan sistem pendukung.

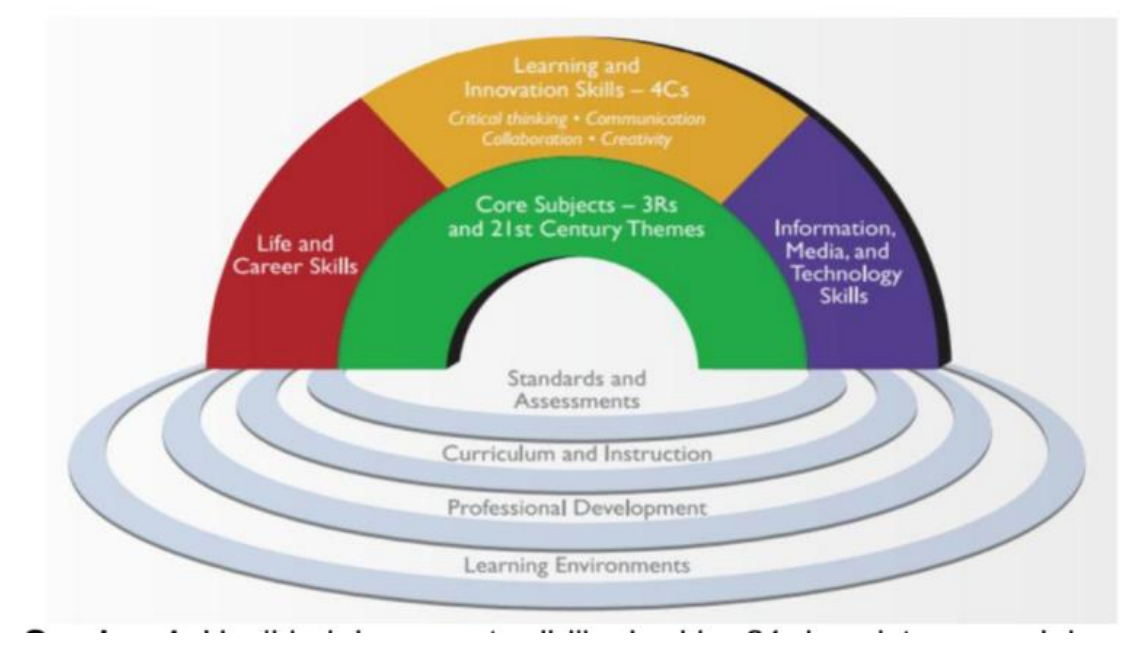

Gambar 5. Hasil Belajar Peserta Didik Abad 21 dan Sistem Pendukung

Dari pengertian di atas ada 4 subjek keterampilan yang dibutuhkan pada abad 21 yaitu (pemikiran kritis, komunikasi, kolaborasi, kreativitas) untuk diterapkan di keterampilan belajar dan inovasi, Kecakapan Hidup dan Karir yang harus ditanamkan dan bagaimana ketrampilan informasi, media, dan teknologi harus diberikan kepada pelajar "cerdas teknologi" kami saat ini.

\section{METODE PENELITIAN}

Pendekatan dalam penelitian ini menggunakan studi literatur, yakni mengelaborasikan secara sistematis dari berbagai konsep tentang kecakapan abad 21 dan model pembelajaran inkuiri bersumber dari jurnal, buku dan penelitian yang relevan guna mengkonstruksi bagaimana model pembelajaran inkuiri mampu mengembangkan kecakapan abad 21.

\section{HASIL DAN PEMBAHASAN}

Sebagaimana telah diuraikan di atas, globalisasi menyangkut seluruh aspek kehidupan masyarakat dan individu anggota masyarakat. Globalisasi menyangkut kesadaran baru mengenai dunia 
sebagai satu kesatuan. Interaksi dan saling tergantungan yang semakin besar dalam era baru perlu dijawab dengan tepat. Kurikulum pendidikan dan proses belajar-mengajar seyogianya mampu mengisi peluang ini serta menjawab tantangan yang ditimbulkannya.

John P. Kotter (1995) dalam bukunya "The New Rules", rule nomor 2 berbunyi: "The globalization of markets and competition is creating enormous change. The new rule is: to succeed, one must capitalize on the opportunities available in the faster-moving and more competitive business environment while avoiding the many hazards inherent in such an environment". Dengan demikian, tamatan pendidikan tinggi seyogianya diperlengkapi agar mampu memanfaatkan peluang-peluang baru yang tersedia dalam era yang baru tersebut; peluang-peluang yang berubah dan bergerak sangat cepat, demikian pula dengan tantangan-tantangan yang ditimbulkannya. Dan hal ini diungkapkan oleh Kotter dalam rule nomor. 7-nya yang berbunyi: "In the increasingly competitive and fast moving global business environment, winners reap big rewards while those who are unable or unwilling to compete can encounter huge problems. The new rule: you have got to be an able competiter. Effective competition requires many things, especially high standards and a strong desire to win". Jadi, produk pendidikan tinggi seyogianya mampu untuk berkompetisi yang salah satu syaratnya adalah memiliki keunggulan-keunggulan tertentu. Jadi kualitas pendidikan memegang peranan yang sangat sentral. Selanjutnya, Kotter mengatakan bahwa pendidikan seumur hidup (life long learning) merupakan tuntutan era baru tersebut. Sebagai rule nomor 8 ia mengatakan: "In a rapidly changing and competitive environment, formal K-12-university education is very important, but insufficient. Success at work demands huge growth after a terminal degree to learn new approaches offers many opportunities for growth for those willing to take some risks and to reflect honestly on their experiences".

Dalam rangka peningkatan mutu pendidikan tinggi Indonesia, maka pelaksanaan tridharma perguruan tinggi seyogianya dilaksanakan dengan benar dalam suasana yang kondusif untuk pengembangannya. Dharma yang pertama (pendidikan dan pengajaran) masih perlu terus dikembangkan pelaksanaannya, termasuk di dalamnya adalah pemanfaatan satuan acara perkuliahan yang rinci serta variasi metode belajar mengajar yang dipergunakan. Salah satu persyaratan utama untuk ini adalah para tenaga pengajar harus tekun dan memiliki motivasi yang tinggi untuk secara terusmenerus menyempurnakan materi perkuliahannya.

Paradigma pembelajaran abad 21 menekankan pada kemampuan peserta didik dalam mencari tahu dari berbagai sumber, merumuskan permasalahan, berpikir analitis dan kerjasama serta berkolaborasi dalam menyelesaikan masalah (Litbang Kemdikbud, 2013). Model pembelajaran yang digunakan adalah model pembelajaran abad 21. Model pembelajaran abad ke-21 sesungguhnya bukan sesuatu yang baru. Model-model pembelajaran yang berpusat pada peserta didik merupakan model pembelajaran abad ke-21. Dalam pembelajaran yang wajib diterapkan adalah pembelajaran dengan pendekatan saintifik. Model pembelajaran yang digunakan adalah model yang mengkodisikan peserta didik dalam suasana pembelajaran yang dapat mengembangkan keterampilan berpikir kritis dan pemecahan masalah, kreativitas dan inovasi, kolaborasi, dan komunikasi. Keempat keterampilan ini adalah merupakan keterampilan abad ke-21. Selain keempat keterampilan tersebut, siswa juga perlu menguasai pengetahuan konten dan sikap ilmiah, memiliki literasi informasi, literasi media, dan literasi teknologi informasi dan komunikasi. Aspek lain yang juga dapat dikembangkan melalui pembelajaran dengan pendekatan saintifik adalah kemampuan beradaptasi dengan berbagai perubahan, inisiatif dan pengarahan diri, keterampilan sosial dan lintas budaya, produktivitas dan akuntabilitas, serta kepemimpinan dan tanggung jawab. Semua hasil belajar abad ke-21 ini akan dapat dikembangkan selama pembelajaran hanya jika pendidik melaksanakan pembelajaran dengan pendekatan saintifik 
dengan tepat dan benar. Salah model pembelajaran dengan pendekatan saintifik yang mampu mengembangkan keterampilan abad ke-21 adalah model inkuiri.

Inkuiri adalah aktivitas yang beraneka ragam yang meliputi melakukan observasi; mengajukan pertanyaan, menguji buku dan sumber informasi lain untuk memeriksa yang diketahui; merencanakan penelitian; meninjau ulang keterangan yang telah diketahui berdasarkan bukti-bukti eksperimen; menggunakan alat untuk mendapatkan hasil, melakukan analisis, dan interpretasi data; mengusulkan pertanyaan, penjelasan, dan prediksi-prediksi; serta mengkomunikasikan hasil. Proses inkuiri membutuhkan identifikasi dari asumsi, menggunakan keterampilan berpikir kritis dan logis, dan pertimbangan dari alternatif penjelasan (National Science Educational Standards, National Research Council, 2002).

Inkuiri (Penyelidikan) adalah pendekatan untuk pembelajaran di mana siswa menemukan dan menggunakan berbagai sumber informasi dan ide untuk meningkatkan pemahaman mereka tentang suatu masalah atau topik. Inkuri adalah suatu model yang lebih dari hanya menjawab pertanyaan atau mendapatkan jawaban yang benar. Ini mendukung penyelidikan, eksplorasi, pencarian, penelitian, mengerjakan tugas dan studi. Penyelidikan tidak berdiri sendiri; ini melibatkan seluruh aktivitas, menarik, dan menantang siswa untuk menghubungkan dunia mereka dengan kurikulum. Meskipun sering dianggap sebagai pembelajaran individu, itu ditingkatkan dengan keterlibatan dengan komunitas peserta didik, masing-masing belajar dari yang lain dalam interaksi sosial. Namun, tanpa bimbingan itu bisa jadi menakutkan (Kuhlthau, Maniotes, \& Caspari, 2007)

Meskipun dosen selalu memasukkan peluang bagi mahasiswa untuk melakukan penelitian dan membuat laporan berdasarkan penelitian mereka, pembelajaran berbasis inkuiri melampaui proses penelitian. Mahasiswa harus dapat melakukan lebih dari sekedar meneliti suatu topik dan melaporkan kembali temuan mereka. Mereka perlu menjadi perencana yang efektif, berpikir kritis, mengevaluasi dan menilai pekerjaan mereka, menavigasi dunia digital, membuat informasi baru dan berbagi temuan mereka dengan yang lain. Pembelajaran berbasis inkuiri memberikan kesempatan bagi siswa untuk:

1. mengembangkan keterampilan yang mereka butuhkan sepanjang hidup mereka

2. belajar untuk mengatasi masalah yang mungkin tidak memiliki solusi yang jelas

3. menangani perubahan dan tantangan untuk pemahaman

4. membentuk pencarian mereka untuk solusi, sekarang dan di masa depan

(Alberta Learning, 2004)

Keterampilan apa yang dibutuhkan mahasiswa sepanjang hidup mereka? Bernie Trilling dan Charles Fidel menulis bahwa tiga perangkat keterampilan yang paling diminati di abad ke-21 meliputi (Trilling \& Fadel, 2009):

1. Keterampilan belajar dan inovasi

2. Keterampilan informasi, media, dan eknologi.

3. Keterampilan hidup dan karier

Jika kampus ingin mempersiapkan mahasiswa untuk belajar di abad ke-21, keterampilan yang tercantum oleh Trilling dan Fadel harus menjadi pusat dari apa yang siswa lakukan di sekolah. Pembelajaran berbasis inkuiri memungkinkan dosen untuk mengatasi keterampilan ini dengan cara yang bermakna dengan aplikasi dunia nyata bagi mahasiswa.

Penyelidikan adalah proses investigasi yang melibatkan mahasiswa dalam menjawab pertanyaan, menyelesaikan masalah dunia nyata, menghadapi masalah, atau mengeksplorasi minat pribadi. (Pappas \& Tepe, 2002) Melalui pembelajaran berbasis inkuiri mahasiswa membangun 
pemahaman, makna dan pengetahuan baru. Pengetahuan baru ini dapat digunakan untuk menjawab pertanyaan, mengembangkan solusi atau mendukung posisi atau sudut pandang dan biasanya disajikan kepada orang lain dan dapat menghasilkan semacam tindakan.

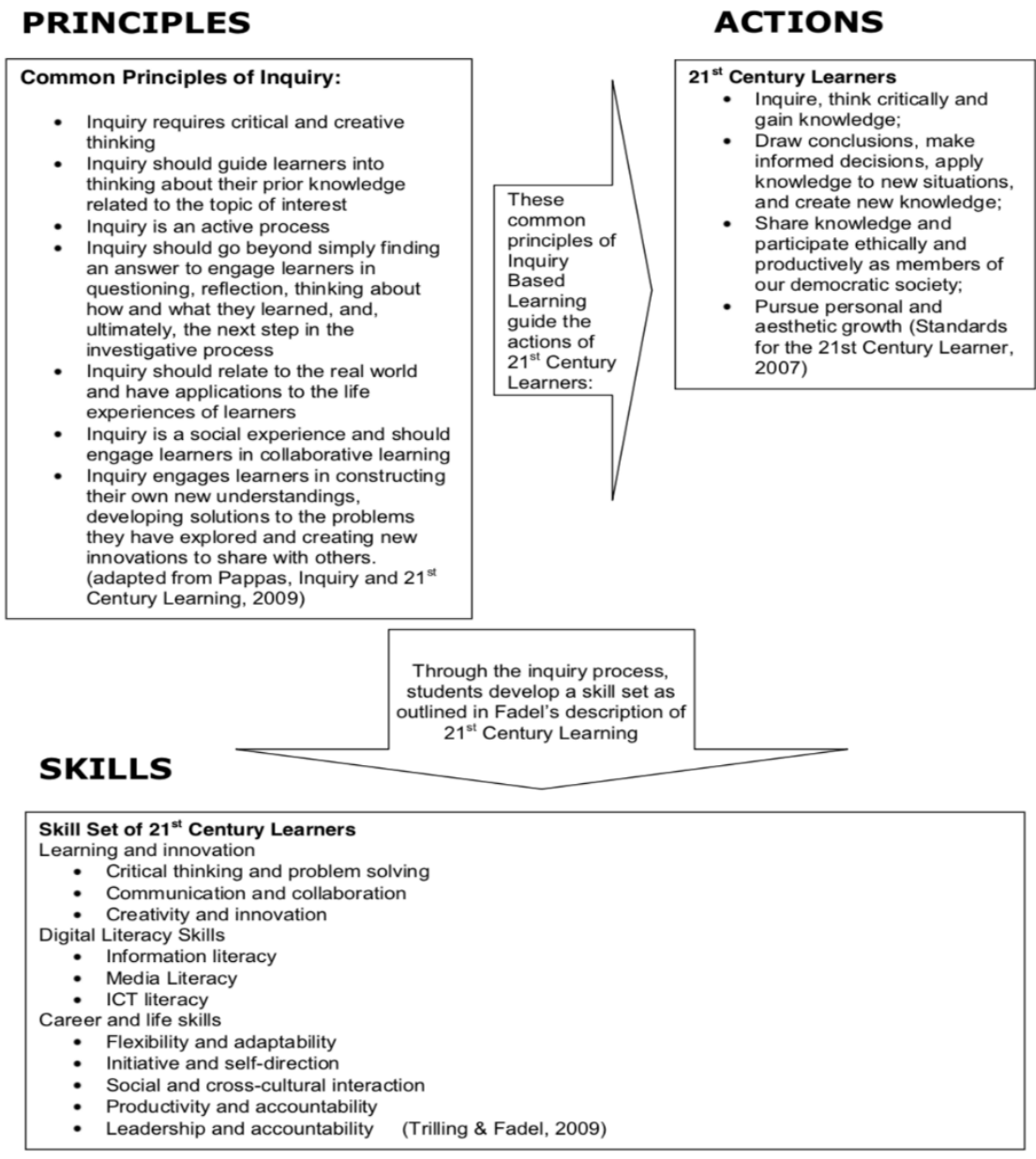

Gambar 6. Alur Proses Inkuiri dalam Pemberdayaan Kecakapan Abad 21

Prinsip umum model Inkuri adalah: 1) Penyelidikan membutuhkan pemikiran kritis dan kreatif; 2) Penyelidikan harus membimbing peserta didik untuk berpikir tentang pengetahuan mereka sebelumnya terkait dengan topik yang diminati; 3) Proses Penyelidikan harus lebih dari sekadar menemukan jawaban untuk melibatkan peserta didik dalam bertanya, merenung, memikirkan bagaimana dan apa yang mereka pelajari, dan, pada akhirnya, langkah selanjutnya dalam proses investigasi; 4) Penyelidikan harus berhubungan dengan dunia nyata dan memiliki aplikasi untuk pengalaman hidup peserta didik; 5) Penyelidikan adalah pengalaman sosial dan harus melibatkan peserta didik dalam pembelajaran kolaboratif; 6) Penyelidikan melibatkan peserta didik dalam membangun pemahaman baru mereka sendiri, mengembangkan solusi untuk masalah yang telah mereka jelajahi dan menciptakan inovasi baru untuk dibagikan kepada orang lain (diadaptasi dari Pappas, Inquiry and 21st Century Learning, 2009) 
Prinsip-prinsip umum Pembelajaran Berbasis Penyelidikan ini memandu tindakan peserta didik Abad 21 yaitu: 1) tanyakan, pikirkan secara kritis dan dapatkan pengetahuan; 2) menarik kesimpulan, membuat keputusan berdasarkan informasi, menerapkan pengetahuan pada situasi baru, dan menciptakan pengetahuan baru; 3) bagikan pengetahuan dan berpartisipasi secara etis dan produktif sebagai anggota masyarakat demokratis;dan 4) Kejar pertumbuhan pribadi dan estetika (American Association of School Librarians, 2007)

Selanjutnya melalui proses inkuiri, siswa mengembangkan keterampilan yang diuraikan dalam uraian Fadel tentang Skill Set of 21st Century Learners yaitu: 1) Learning and innovation yang terdiri dari berpikir kritis dan menyelesaikan masalah, komunikasi dan kolaborasi, kreativitas dan inovasi; 2) Digital Literacy Skill yang terdiri dari literasi informasi, literasi media dan literasi TIK ; 3) Career and life skills yang terdiri dari fleksibilitas dan kemampuan beradaptasi, inisiatif dan pengarahan diri sendiri, interaksi sosial dan lintas budaya, produktivitas dan akuntabilitas, kepemimpinan dan akuntabilitas (Drayton \& Falk, 2001). Pembelajaran berbasis inkuiri memiliki karakter berikut (Drayton \& Falk, 2001):

1. Pertanyaan muncul dari masalah otentik (kehidupan nyata) dalam konteks kurikulum dan / atau komunitas.

2. Penyelidikan memanfaatkan rasa ingin tahu siswa (Alberta Learning, 2004)

3. Data dan informasi secara aktif digunakan, ditafsirkan, disempurnakan, dicerna dan dibahas.

4. Dosen ,mahasiswa, dan dosen-pustakawan berkolaborasi.

5. Komunitas dan masyarakat terhubung dengan penyelidikan.

6. Dosen/mahasiswa, perpustakaan memberi teladan perilaku penanya.

7. Dosen/mahasiswa, perpustakaan menggunakan bahasa inkuiri secara berkelanjutan.

8. Mahasiswa mempunyai kepemilikan atas pembelajaran mereka.

9. Pustakawan / dosen memfasilitasi proses pengumpulan dan penyajian informasi.

10. Dosen/mahasiswa, perpustakaan menggunakan teknologi untuk mengajukan pertanyaan. •

11. Dosen/mahasiswa, perpustakaan menerima pertanyaan baik sebagai konten maupun pedagogi.

12. Dosen/mahasiswa, perpustakaan berinteraksi lebih sering dan lebih aktif daripada selama pengajaran tradisional.

13. Ada waktu yang dapat diidentifikasi untuk pembelajaran berbasis inkuiri.

Model pembelajaran, Penyelidikan, mendukung pekerjaan dosen dan mahasiswa dan dapat digunakan dalam berbagai cara termasuk:

1. A scaffold for instruction yang menguraikan keterampilan dan strategi yang perlu diajarkan secara eksplisit di setiap fase proses.

2. A gauge for feelings yang meyakinkan mahasiswa bahwa mereka akan merasakan berbagai perasaan di seluruh model (antusiasme, ketakutan, frustrasi dan kegembiraan dan bahwa perasaan ini adalah bagian normal dari proses penyelidikan)

3. A common language untuk dosen dan mahasiswa membantu mahasiswa menginternalisasi model, untuk berbicara tentang proses pembelajaran yang terlibat dan untuk meningkatkan komunikasi yang efektif di antara semua penanya di kampus.

4. A guide for students dalam menggunakan pendekatan analitis yang mencakup semua fase dalam proses penyelidikan. Tanpa mempelajari proses inkuiri, mahasiswa sering mengembangkan pandangan yang sangat terbatas dan sempit tentang inkuiri. 
5. A guide for monitoring di mana dosen menilai seberapa efektif mahsiswa terlibat dalam proses inkuiri, seberapa dalam mereka memahaminya, dan seberapa efektif proses tersebut telah diurutkan di seluruh kelas.

Penelitian menunjukkan bahwa inquires mengikuti pola kognitif dan afektif umum. Namun, proses penyelidikan bukan langkah linier atau kunci. Ini sangat individual, nonlinear, fleksibel dan lebih rekursif daripada yang mungkin disarankan dalam model tradisional dari proses penelitian. Inquires berpengalaman cenderung melakukan lebih banyak-looping back karena mereka merasa nyaman dengan prosesnya. Dengan merefleksikan prosesnya, semua peserta didik dapat merasa nyaman dengan sifat inkuiri nonlinier, individual, fleksibel dan rekursif (Alberta Learning, 2004).

Sintak (tahap) Inkuri yang diekomendaasikan sebagaimana gambar 4 yaitu:

1. Reflecting on the process phase, ini merupakan bagian integral dari semua fase dalam Model Penyelidikan - Perencanaan, Pengambilan, Pemrosesan, Pembuatan, Pembagian dan Evaluasi — dan mencakup ranah afektif dan kognitif yang terkait dengan metakognisi.

2. Planning Phase (fase paling penting). Penyelidik harus memahami bahwa tujuan dasar dari proyek pembelajaran berbasis inkuiri adalah untuk mengembangkan keterampilan "learning to learn skills". Pembelajaran berbasis inkuiri dimulai dengan minat atau keingintahuan para penanya tentang suatu topik.

3. Retrieving Phase. Penyelidik selanjutnya berpikir tentang informasi yang mereka miliki dan informasi yang mereka inginkan. Penyelidik mungkin perlu meluangkan banyak waktu mengeksplorasi dan memikirkan informasi yang telah mereka temukan sebelum mereka datang ke "fokus" untuk penyelidikan mereka.

4. Processing Phase. Fase ini dimulai ketika penanya telah menemukan "fokus" untuk penyelidikan. Fokus adalah aspek area topik yang diputuskan oleh penyelidik untuk diselidiki.

5. Creating Phase. Mengelola informasi, memasukkan informasi ke dalam kata-kata sendiri dan membuat format presentasi adalah tugas selanjutnya dalam proses.

6. Evaluation Phase, jika siswa telah diberikan dukungan yang cukup selama proses inkuiri, mereka bangga dengan produk mereka dan ingin membagikannya, terlepas dari format atau audiensnya.

\section{KESIMPULAN DAN SARAN}

Keterampilan abad ke-21 adalah keterampilan penting yang harus dikuasai oleh semua orang dalam menghadapi kehidupan di abad ke-21. Beberapa organisasi telah mendefinisikan tentang keterampilan abad ke-21. Semua definisi tersebut mengandung prinsip- prinsip yang sama. Keterampilan abad ke- 21 terdiri atas keterampilan berpikir kritis dan pemecahan masalah, kreativitas dan inovasi, kolaborasi, dan komunikasi. Keterampilan ini harus dikuasai oleh peserta didik agar dapat menghadapi tantangan di abad ke-21. Penguasaan keterampilan ini oleh peserta didik dapat dilakukan oleh pendidik dengan melakukan reformasi terhadap proses pembelajaran. Pembelajaran yang berpusat pada peserta didik atau pembelajaran dengan pendekatan saintifik merupakan jawaban atas pertanyaan bagaimana mengembangkan keterampilan abad ke-21 pada peserta didik. Salah satu model pembelajaran dengan pendekatan saintifik adalah model pembelajaran Inkuri. Dengan Prinsipprinsip umum Pembelajaran Berbasis Penyelidikan ini memandu tindakan peserta didik Abad 21. Selanjutnya melalui proses inkuiri, peseta didik mengembangkan keterampilan Skill Set of 21st Century Learners yaitu: 1) Learning and Innovation yang terdiri dari berpikir kritis dan menyelesaikan masalah, komunikasi dan kolaboras,i kreativitas dan inovasi; 2) Digital Literacy Skill yang terdiri dari literasi 
informasi, literasi media dan literasi TIK; 3) Career and Life Skills yang terdiri dari fleksibilitas dan kemampuan beradaptasi, Inisiatif dan pengarahan diri sendiri, Interaksi sosial dan lintas budaya, Produktivitas dan akuntabilitas, Kepemimpinan dan akuntabilitas

\section{DAFTAR PUSTAKA}

American Association of School Librarians. (2007). Standards for the 21st Century Learner in Action. Retrieved November 17, 2010, from: http://www.ala.org/ala/mgrps/divs/aas//guidelinesandstandards/learningstandards/standar ds.cfm

Alberta Learning. (2004). Focus on inquiry: A teacher's guide to implementing inquiry-based learning. Edmonton, Canada: Alberta Learning and Teaching Resources Branch

Al Musawi, A., Asan, A., Abdelraheem, A., \& Osman, M. (2012). A case of web-based inquiry learning model using learning objects. The Turkish Online Journal of Educational Technology, 11 (1), 1-9.

Ball, A., Joyce, H. D., \& Butcher, D. A. (2016). Exploring 21st century skills and learning environments for middle school youth. International Journal of School Social Work, 1(1), 1-25.

Binkley, M., Erstad, O., Herman, J., Raizen, S., Ripley, M, \& Rumble, M. (2010). Draft White Paper 1 Defining 21st Century Skills and Assessments. Melbourne, Australia: Assessment and Teaching of 21st Century Skills. Retrieved from http://cms.education.gov.il/NR/rdonlyres/19B97225-84B14259-B423- 4698E1E8171A/115804/defining21stcenturyskills.pdf

Bishop, A. P., Bertram, B.C., Lunsford, K.J., Jones, M.C., Nazarova, M., Linderman, D,... Brock A. (2004). Supporting community inquiry with digital resources. Journal of Digital Information, 5 (3).

Blumberg, P. (2000). Evaluating the evidence that problem-based learners are self-directed learners: A review ofthe literature. In D. H. Evensen \& C. E. Hmelo. (Eds.), Problem based learning: $A$ research perspectiveon learning interactions (pp. 199-266). Mahwah, NJ: Lawrence Erlbaum Associates.

Cassel, R. N. \& Kolstad, R. (1998). Critical job-skill requirements for the 21st century: Living and working with people. Journal of Instructional Psychology, 25, (3), 176.

Chen, C-H., \& Chen, C-Y. (2012). Instructional approaches on science performance, attitude and inquiry ability in a computer-supported collaborative learning environment. The Turkish Online Journal of Educational Technology, 11 (1), 113-122.

Dede, C. (Eds.). (1998). ASCD Yearbook: Learning with Technology. Alexandria, VA:Association for Supervision and Curriculum Development.

Drayton, B., \& Falk, J. (2001). Tell-Tale signs of the inquiry-oriented classroom. NASSP Bulletin, 85, 2434.

Eick, C.J. \& Reed, C.J. (2002). What makes an inquiry oriented science teacher? The influence of learning histories on student teacher role identity and practice. Science Teacher Education, 86, 401-416. 
Ekdahl, M., Farquharson, M. Robinson, J. \& Turner, L. (2010). The Points of Inquiry: A Framework for Information Literacy and the 21st Century Learner. Vancouver, BC: British Columbia Teacher Librarians' Association

Holaday, S. D. \&. Buckley, K. M. (2008).Addresing challenges in nursing education through a clinical instruction model based on hybrid inquiry based learning framework. Nursing Education Perspective, 29(6), 353-358.

Halpern, D. F. (2014). Thought and Knowledge: An Introduction to Critical thinking (5th ed). New York: Phsycology Press.

Kotler, J. P. (1995). The New Rules: How to Succeed in Today's Post-corporate World. New York: Free Press

Kühne, B. (1995). The Barkestorp project: Investigating school library use. School Libraries Worldwide, $1(1), 13-27$.

Kuhlthau, C. C., Maniotes, L. K., \& Caspari, A. K. (2007). Guided Inquiry Learning in the 21st Century. Westport: Libraries Unlimited Inc.

Levy, P. O. Aiyegbayot \& S. Little. (2009). Desingining for inquiry-based learning with the Learning Activity Management System. Journal of Computer Assisted Learning, 25, 238-251

Miranda, R. J. \& Hermann, R. S. (2012). An integrated instructional approachto facilitate inquiry in .the classroom. Science Scope, 35(8), 66-72.

Montero, B., Watts, F., \& Garcia-Carbonell, A. (2007). Discussion forum interactions: Text and context. System, 35, 566-582.

National Research Council. (2008). Research on future skill demands: A workshop summary. Washington, DC: The National Academies Press.

National Research Council. (2010). Exploring the intersection of science education and 21st century skills: A workshop summary. Washington, DC: The National Academies Press.

National Research Council. (2011). Assessing 21st century skills: Summary of a workshop. Washington, DC: The National Academies Press. Retrieved from http://ctl.sri.com/publications/downloads/21st_century_skills.pdf

National Research Council. (2012). Education for life and work: Developing transferable knowledge and skills in the 21st century. Washington, DC: The National Academies Press.

Olson, L. (2016). Ambiguity and preparation for workforce clouds efforts to equip students for future. Education Week, 25 (38), 18-20

Pappas, M. L. (2009, May). Inquiry and 21st Century Learning. School Library Media Activities Monthly, pp. 49-51.

Pappas, M. L., \& Tepe, A. E. (2002). Pathways to Knowledge and Inquiry Learning. Greenwood Village: Libraries Unlimited. 
Sanjaya, W. (2008). Strategi Pembelajaran Berorientasi Standar Proses Pendidikan. Jakarta: Kencana Prenada Media Group.

Soltis, R., Verlinden, N., Kruger, N., Carroll, A., \& Trumbo, T. (2015). Process-oriented guided inquiry learning strategy enhances students' higher level thinking skills in a pharmaceutical sciences course. American Journal of Pharmaceutical Education, 79(1), 11

Sparks, E. \& Waits, M. J. (2011). Degrees for What Jobs? Raising Expectations for Universities and Colleges in A Global Economy. Washington DC: National Governors Association, Center for Best Practices.

Sukmana, A. (2018). Mengembangkan pembelajaran abad ke-21 di unpar. Majalah Parahyangan, 5 (1), $14-15$.

The Partnership for 21st Century Learning. (2015). P21 Framework Definitions. Diakses 3 November 2015 dari http://www.p21.org/storage/docume nts/docs/P21_Framework_ Definitions_New_Logo_2015.

The Partnership for 21st Century Skills. (2002). Framework for 21st Century Learning. Retrieved from http://www.p21.org/overview/skills-framework

The Partnership for 21st Century Skills. (2008). 21st Century Skills, Education dan Competitiveness: A Resource and Policy Guide. Diakses 1 Desember 2015 dari http://www.p21.org/storage/docume nts/21st_century_skills_education and_competitiveness_guide.pdf

Trilling, B and Hood, P. (1999). Learning, technology, and education reform in the knowledge age or "We're wired, webbed, and windowed, now what? Educational Technology, 39(3), 5-18. (https://www.wested.org/online_pubs/ learning_technology.pdf.), diakses tanggal 24 Oktober 2019

Tucker, R. B. (2001). Innovation: The new core competency. Strategy \& Leadership, 29(1),1114. https://doi.org/10.1108/10878570110694616

Trilling, B., \& Fadel, C. (2009). 21st Century Skills: Learning for Life in Our Times. San Francisco: Jossey-Bass

Villavicencio, J. (2000). Inquiry in kindergarten. Connect Magazine, 13(4), Synergy Learning Publication.

What is Project Based Learning. (2005). Retrieved December 10, 2010, from Project Based Learning: The Online Resource for PBL: http://pbl-online.org/default.htm 